\title{
ENVIRONMENTS INDUCING CHANGES IN AMOUNT OF DNA IN FLAX
}

\author{
I. O. JOARDER, Y. AL-SAHEAL, J. BEGUM and A. DURRANT \\ Department of Agricultural Botany, University College of Wales, Aberystwyth
}

Received 24.viii.74

\begin{abstract}
Summary
The induced large $(L)$ genotroph of the flax variety Stormont Cirrus has 16 per cent more DNA than the induced small $(S)$ genotroph. Their plant weights are stable in a wide range of environments but the amounts of DNA can be reverted in both $L$ and $S$ towards the intermediate value by growing the plants at a lower temperature for the first 5 weeks from sowing. After three generations there is no measurable difference as observed by Feulgen photometry in the amount of DNA between $L$ and $S$. The reversion can be stopped at any point by growing the plants of the next generation in warmer conditions so that any number of plants can be obtained containing any desired amount of nuclear DNA up to the inducible limits. Environments of field and greenhouse experiments alter the amounts of DNA, and one environment raised the overall DNA difference between plants to 23 per cent. The effect of the seed multiplication environment must be taken into account when comparing results from different laboratories.
\end{abstract}

\section{INTRODUCTION}

Heritable changes in plant weight induced by growing plants of some flax varieties (Linum usitatissimum) in a moderately heated greenhouse with different fertilisers, are accompanied by heritable changes in amount of nuclear DNA (Durrant, 1962, 1972; Evans, 1968). A large type of plant ( $L$ genotroph) obtained by growing plants of the variety Stormont Cirrus (a plastic genotroph, $P l$ ), with additional soil nitrogen, is up to five times larger and has 16 per cent more nuclear DNA than a small type of plant ( $S$ genotroph) obtained with additional phosphorus applied to soil of lower $p \mathrm{H}$. The difference in amount of DNA is due to differences in number of repeated DNA sequences (Cullis, 1973; Timmis and Ingle, 1973). Untreated plants $(P l)$ are intermediate in plant weight and amount of DNA so that the specific inducing environments of nitrogen and phosphorus induce symmetrical changesin plus and minus directions. $L$ and $S$ are stable in inheritance and are two genetically distinct types which have been maintained for many generations, and theybreed true irrespective of the soil nutrients subsequently applied.

No environment has been found which will change $L$ and $S$ plant weights back to the original $P l$ plant weight, but some reversion in their amounts of DNA towards the $P l$ value occurs if they are grown at a lower temperature (Durrant and Jones, 1971). Normally $L$ and $S$ are grown for the first 5 weeks in a greenhouse, and they may be transplanted outside afterwards. If they are grown out of doors from the time of sowing, after one generation the DNA difference drops to 10 per cent, and after two generations to 5 per cent, the amount in $L$ decreasing, and in $S$ increasing. 
Some changes in amounts of DNA in $L$ and $S$ have been found in other experiments, and they are described here with the objective of defining more precisely the type of environment which will maintain the full 16 per cent difference in DNA over generations. This is essential if similar results are to be obtained from DNA studies on plants multiplied up at different places.

\section{THE ENVIRONMENTS}

Different environments are used in the cultivation of flax genotrophs. One type is used for maintaining the $P l$ genotroph unchanged. Another type consists of the inducing environments which bring about the heritable changes in $P l$. A third type, with which we are concerned here, is used to maintain the $L$ and $S$ genotrophs and is described in Enl below. The other environments, En2 to En5, are modifications of En1.

\section{(i) Environment for maintaining the $\mathrm{L}$ and $\mathrm{S}$ genotrophs (EnI)}

Seed is sown in the first week of April in 18-cm pots, five seeds to a pot, containing compost of 7 parts soil, 3 of gravel and 2 of peat to which John Innes fertiliser No. 1 has been mixed at the rate of $0.9 \mathrm{~kg}$ to $6018-\mathrm{cm}$ pots. The compost $p \mathrm{H}$ is about 6.5 and no lime is added. The pots are kept in a greenhouse with sufficient additional heating to maintain the temperature well above $0^{\circ} \mathrm{C}$ at night and to bring it to about $16^{\circ} \mathrm{C}$ on dull days. Normally, heating is turned off at the end of May and the plants either mature and set seed in the greenhouse, or the pots are placed outside for several weeks and brought in later to ripen the seed. Seed will ripen out of doors but a more uniform and better quality seed sample is obtained, particularly in a damp season, if the plants are brought in.

\section{(ii) Environment for inducing $D \mathcal{N} A$ reversion in the $\mathrm{L}$ and $\mathrm{S}$ genotrophs (En2)}

This environment is the same as Enl except that the pots are placed out of doors immediately the seed is sown and they remain outside almost to maturity when they are brought into an unheated greenhouse to ripen the seed.

\section{(iii) Environment for field experiments with an initial period in a greenhouse (En3)}

This environment simulates as far as possible environment Enl (for maintaining the $L$ and $S$ genotrophs) and the same compost is used, but the seed is sown in plastic pots, about $5 \mathrm{~cm}$ wide and $6.5 \mathrm{~cm}$ deep, for the purpose of rearing large numbers of plants for easy transplantation into the field. One seed is sown per pot during the first 2 weeks of April, and the pots, which are aggregated into trays, are kept in an unheated greenhouse for 4 or 5 weeks depending on plant growth. They are then placed outside and, ideally, a week later the plants are transplanted into the field. The difference in growth between plants in moderately heated and unheated greenhouses is small compared with the major difference in growth between plants inside and outside a greenhouse. 
(iv) Environment for field experiments without an initial period in a greenhouse (En4)

This environment for inducing DNA reversion in $L$ and $S$ in field experiments, is the same as En3 but the trays are placed outside imediately the seed is sown in April, simulating environment En2. The plants grow more slowly and they are transplanted about 8 weeks from sowing.

\section{(v) Environment for pot experiments (En5)}

This environment is never used for multiplication and maintenance of stocks. Its purpose is to grow as many plants as quickly as possible in the smallest area where they are hastened to maturity to obtain more than one generation per year, or for recording the $h$ capsule character (Durrant and Nicholas, 1970). The same compost is used as in the other environments but 10 seed are sown per $13-\mathrm{cm}$ pot in an unheated or heated greenhouse, wherever there is space. The plants remain in the same place till maturity, and they are tall, thin, mostly unbranched with a small group of capsules at the top of each.

\section{Heritable changes in DNA induced by the EnVIRonMents}

The amount of nuclear DNA was measured in the immediate progeny of the treated plants after one, two or three generations in the environment under test, so that any observed changes induced by the environment must have been transmitted to the next generation at least. Feulgen photometric measurements, following the procedure described by Evans (1968), were made on the shoot apices of 3-week-old plants which were grown for this purpose in an environment similar to Enl except that $13-\mathrm{cm}$ pots were used instead of 18-cm. Previous tests (Durrant and Jones, 1971) have shown that at this age there is no measurable difference in the result whether they are grown in En1 or out of doors in En2.

In all studies at least two sets of ancestral lines are maintained and treated similarly but they are otherwise kept separate and they are not intercrossed. Two to six plant replicates of each treatment within each ancestral line were assayed, a complete replicate of all treatments and both genotrophs being taken at any one time. Tables of individual plant values have been omitted because the error variation was about the same as in previously described experiments where details are given (Durrant and Jones, 1971).

\section{(i) Environment EnI}

The $L$ and $S$ genotrophs have been maintained in environment Enl for 17 generations. Measurements have been made on the last eight generations and the difference in amount of DNA between them has remained consistently at 16 per cent. This environment can therefore be used as a control against which the effects of the other environments can be measured.

\section{(ii) Environment En2}

In this environment, which is the same as Enl except that the plants are grown at the lower outdoor temperature, the DNA amounts in $L$ and $S$ 
reverted in two previous experiments, where different batches of plants grown in different years were used, to a difference of about 5 per cent after two generations. Timmis (1971) examined one of these sets after three generations in En2 and found no significant difference in DNA amount between $L$ and $S$.

During this period, lines were being generated according to the pattern in table 1 , which allows practically independent comparisons to be made within and between generations. For example, plants in their second generation $\left(\mathrm{G}_{2}\right)$ in En2 in 1968 are descended along a different line from those in $G_{2}$ in 1967, and were grown for the first and second generations respectively in $\mathrm{En} 2$ in different years. In 1968 the four types, $G_{0}$ to $G_{3}$, are also descended along different lines.

TABLE 1

Generations of $\mathrm{L}$ and $\mathrm{S}$ in En1 and En2 environments. In $1971(b)$ the lines in En2 are returned to the En1 environment

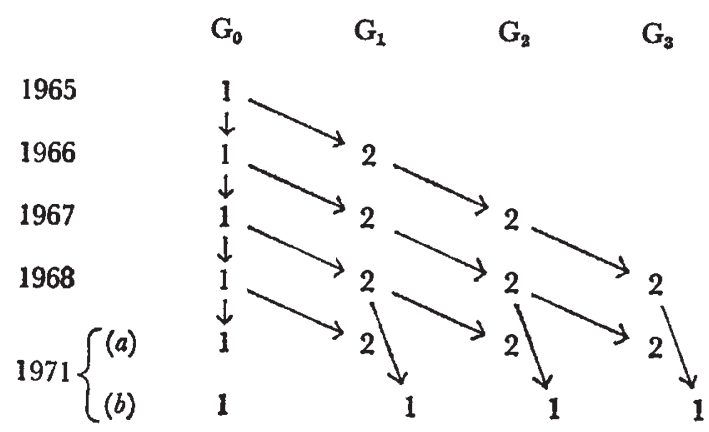

Key: 1, 2-Enl and En2 environments. $\mathbf{G}_{0}$ - Lines grown in Enl only. $\mathbf{G}_{1}$ to $\mathbf{G}_{3}$ - Lines grown in $\mathrm{En} 2$ for 1 to 3 generations. 1965 to 1971 -Years in which the generations were grown.

The DNA amounts were measured in the progeny of the 1968 plants, $G_{0}$ to $G_{3}$ and in the progeny of another set generated in 1971, denoted 1971 (a) in table 1 and fig. 1 . There is an additional set in 1971, departing from the general pattern where the progeny of the 1968 plants were all grown in Enl, denoted 1971 (b) in table 1 and fig. l, to determine whether the effects of $\mathrm{En} 2$ on previous generations could be reverted by returning them to Enl, or whether they remain fixed at their respective 1968 values by the Enl environment.

The three sets of data (fig. 1) give practically identical results. In 1968, after three generations in En2, the reversion is complete, within the limits of resolution of the method, and again in 1971 (71 (a), fig. 1). The third graph $(71(b))$ shows that the reversion can be stopped at any point simply by growing the plants in Enl again. The reversion over generations is highly significant $(\mathrm{P}<1$ per cent) in each case.

\section{(iii) Environments En 3 and En4}

The En3 environment is used in field experiments in which $L$ and $S$ are required to remain unchanged, and is a compromise between the Enl 


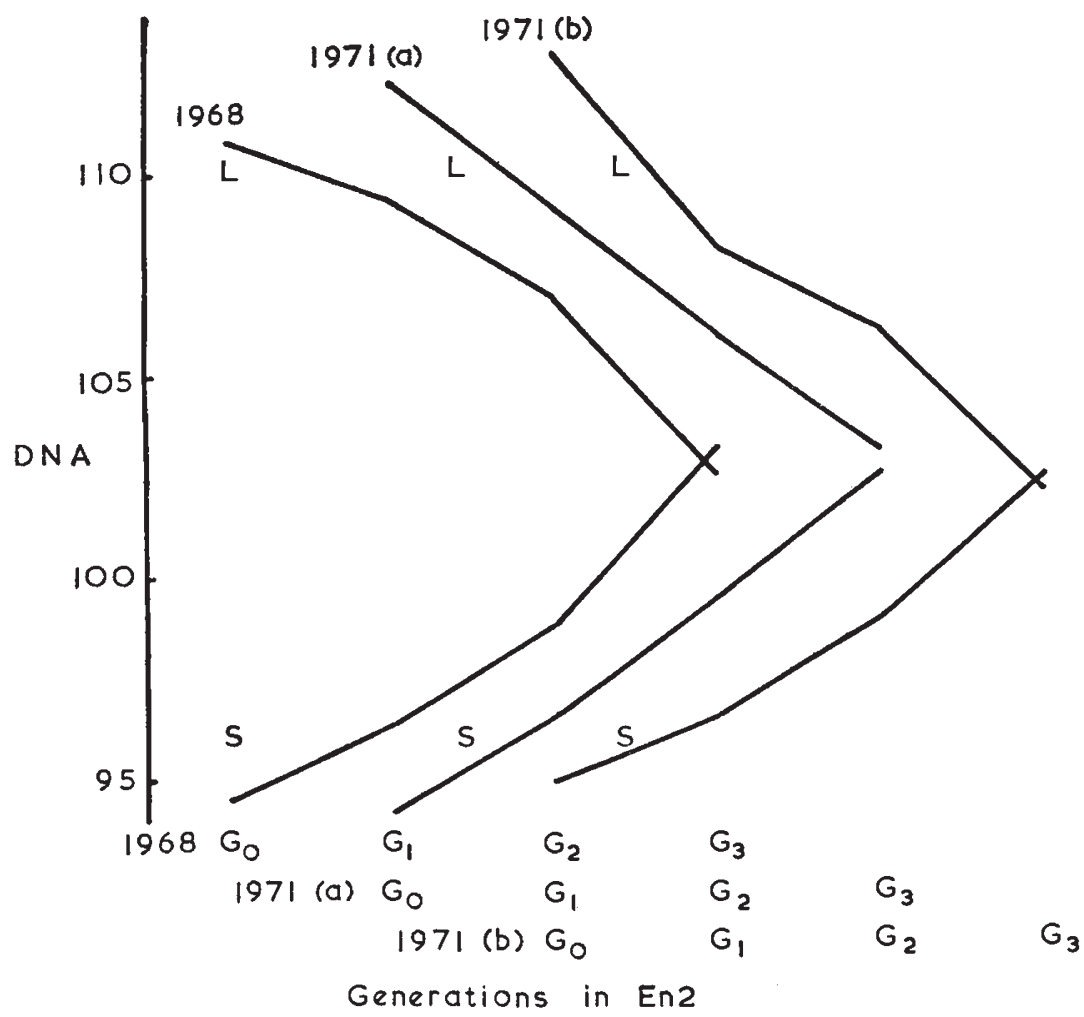

Fig. 1.-Amounts of nuclear DNA (arbitary units) in $L$ and $S$ genotrophs grown in En2 environment for $0,1,2,3$ generations. $G_{0}$ plants were grown in the control Enl environment. The graphs are displaced for clarity. $1971(a)$ is a repeat of 1968. In $1971(b)$ all lines have been returned to Enl for one generation. See table 1 and text for further details.

TABLE 2

Amounts of DNA (arbitary units) in control $\mathrm{L}$ and $\mathrm{S}$ plants grown in En1 environment $\left(G_{0}\right)$ and in $\mathrm{L}$ and $\mathrm{S}$ plants grown in En 3 and En4 environments for four generations $\left(G_{4}\right)$

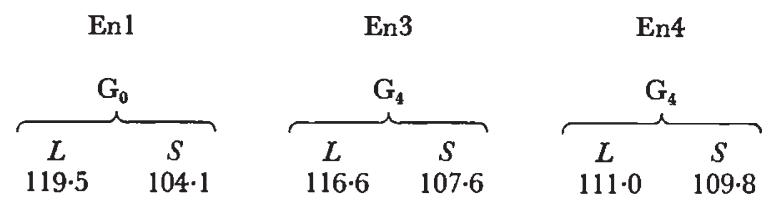

environment and practical considerations. Similarly, the En4 environment is used for field experiments where a deliberate reversion of DNA in $L$ and $S$ is required, and is a practical alternative to $\mathrm{En} 2$.

$L$ and $S$ were grown in En3 and En4 for four generations $\left(\mathrm{G}_{4}\right)$ and the amounts of DNA in their progeny were compared with samples of control $L$ and $S$ plants from the Enl environment $\left(\mathrm{G}_{0}\right)$. Table 2 shows that En4 gives complete reversion after four generations as was intended, but En3 has induced partial reversion $(\mathbf{P}<0.01)$ which was not intended. Hence 
En4 is a practical alternative to En2, but this particular En3 environment at least cannot be used in place of Enl.

\section{(iv) Environment En5}

This is the environment where plants are crowded together in $13-\mathrm{cm}$ pots in a greenhouse. The plants analysed were from two separate experiments, grown in different places in different years and at different times of the year. From the first experiment the progeny of $L$ and $S$ plants grown for two generations $\left(G_{2}\right)$ in En5 were assayed, and from the second the progeny of plants grown for three generations $\left(G_{3}\right)$ in En5 were assayed, together with control $L$ and $S$ plants from the Enl environment $\left(\mathrm{G}_{0}\right)$.

Table 3 shows $L$ and $S$ both increasing in amount of DNA. The overall difference between $L$ and $S$, and the mean increase over generations $\left(\mathrm{G}_{0}\right.$ to

TABLE 3

Amounts of DNA (arbitary units) in control $\mathrm{L}$ and $\mathrm{S}$ plants grown in En1 environment $\left(G_{0}\right)$ and $\mathrm{L}$ and $\mathrm{S}$ plants grown in En5 environments for two and three generations $\left(G_{2}, G_{3}\right)$. Mean amounts for $\mathrm{L}$ and $\mathrm{S}$ in brackets.

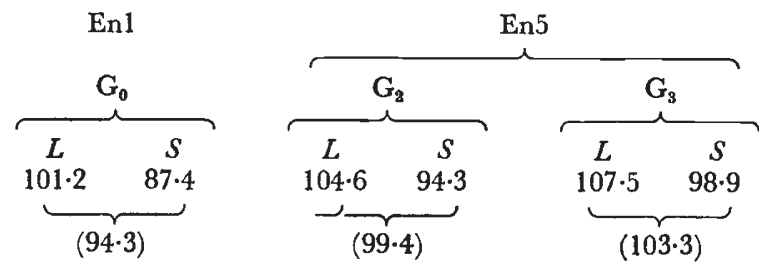

$\mathrm{G}_{3}$ ), are highly significant $(\mathrm{P}<0.01)$, but the convergence of $L$ and $S$ is not significant, nor is its linear component when tested separately. The percentage difference between $L$ and $S$ at $\mathrm{G}_{0}$ is $15 \cdot 8$, at $\mathrm{G}_{3}$ it is 8.8 . $L$ at $\mathrm{G}_{3}$ has 23 per cent more DNA than $S$ at $\mathrm{G}_{0}$.

\section{Discussion}

$L$ and $S$ genotrophs have been grown in several experiments in the En2 environment where the plants are grown out of doors from sowing, and each time the amount of DNA in both has gradually reverted towards the intermediate amount possessed by the original variety before the changes were environmentally induced in the first place. The amount of reversion each generation is precise and repeatable, and at the end of the third generation there is no difference measurable by Feulgen photometry in amount of DNA between $L$ and $S$. The reversion can be stopped at any point by growing the plants of the next generation in Enl again, i.e. by growing the plants for the first 5 weeks in a heated greenhouse, so that the two environments Enl and En2 together provide the means for rearing any number of plants containing any desired amount of nuclear DNA, up to the inducible limits, and maintaining these amounts, as far as can be seen, over any number of generations. In no case has the induced plant weights of $L$ and $S$ reverted to the original plant weight, nor have there been any other observable changes in their phenotypes at the third generation $\left(G_{3}\right)$. 
It may be therefore that the varying DNA is largely inert. The difference found by Timmis and Ingle (1973) in number of rRNA genes between $L$ and $S$ would not be detected by Feulgen photometry, and this rDNA difference may still be present at $\mathrm{G}_{3}$ and perhaps determines the plant weight difference.

Environment En4, where the plants are grown out of doors in small pots, has the same effect as En2 and can be used in its place in field experiments. Environment En3, used to replace En1 in field experiments is much less satisfactory for in terms of DNA amount its affect is somewhere between En1 and En2, that is, there is slow but significant reversion. En3 could probably be improved, by increasing the time in the greenhouse, by additional heating or perhaps by enriching the compost.

The initial changes in DNA amount induced by the soil nutrients (Durrant, 1962) are rapid, occurring within 5 weeks from sowing. The changes described here are gradual, taking several generations, and though no changes in plant weight, or in other characters, have been observed they are no doubt accompanied by nuclear changes involving controlling elements of some kind. Both nuclear and cytoplasmic factors in $P l$ not possessed by another variety, Royal for example, are necessary for the initial induced changes to occur (Durrant and Timmis, 1973). The DNA in $L$ and $S$ decrease and increase respectively in En2, which suggests that this environment destabilises the hitherto stable induced changes.

Seed multiplied elsewhere to produce sufficient material for DNA studies is hardly likely to be grown in environments identical to those used here, which must be taken into account when comparing results from different laboratories. A completely defined controlled environment would be helpful but it would need to be tested for several generations.

\section{REFERENGES}

CULlis, C. A. 1973. DNA differences between flax genotrophs. Nature, 243, 515-516.

DURRANT, A. 1962. The environmental induction of heritable change in Linum. Heredity, $17,27-61$.

DURRANT, A. 1972. Studies on reversion of induced plant weight changes in flax by outcrossing. Heredity, 29, 71-81.

DURRANT, A., AND JONEs, r. w. A. 1971. Reversion of induced changes in amount of nuclear DNA in Linum. Heredity, 27, 431-439.

DURRant, A., AND Nicholas, D. B. 1970. An unstable gene in flax. Heredity, 25, 513-527. DURRANT, A., AND TIMMIS, J. N. 1973. Genetic control of environmentally induced changes in Linum. Heredity, 30, 369-379.

Evans, G. M. 1968. Nuclear changes in flax. Heredity, 23, 25-38.

rImMIs, J. N. 1971. Ph.D. Thesis, U.C.W., Aberystwyth.

TIMMIS, J. N., AND INGLE, J. 1973. Environmentally induced changes in rRNA gene redundancy. Nature New Biol., 244, 235-236. 